\title{
Chinese preschoolers' risk-taking behaviors: a tripartite relation
}

Jun $\mathrm{Hao}^{*}$ and Yeh Hsueh

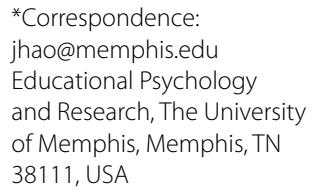

\begin{abstract}
Unintentional injury has been a leading threat to Chinese children. Children's risktaking is influenced by their evaluation of risky behavior and related safety knowledge, which also vary considerably by child and family characteristics. In light of the Health Belief Model, the current study (1) proposes and tests a tripartite relation among Chinese preschoolers' safety knowledge, evaluations of risk, and risk-taking behavior; (2) examines how the tripartite relation varies by child, family, and residential characteristics. Preschooler-caregiver dyads $(N=217)$ completed questionnaires and interviews. The results confirmed the existence of the tripartite relation in Chinese preschoolers. Rural children, children with siblings, and those from families with low SES or high mobility, all demonstrated less safety knowledge, viewed risk-taking behaviors as unlikely to result in injury, and exhibited more risky behaviors. This study is the first to consider these issues in a sample of preschoolers. The findings suggest that preschool injury prevention programs should address preschoolers' safety knowledge and evaluative skills along with those of their caregivers.
\end{abstract}

Keywords: Unintentional injury, Risk-taking behavior, Evaluation, Safety knowledge, Chinese preschoolers, Family

\section{Background}

Young children's risk-taking behaviors are likely to lead to unintentional injury (Zeedyk and Wallace 2003). As they reach preschool age, children become more independent and receive less direct parental supervision than before (Boles et al. 2005; Morrongiello et al. 2016). Numerous injuries have been reported when preschoolers were left unsupervised while engaging in injury-causing risky behaviors (Morrongiello and Lasenby 2007). The decreased parental supervision requires an increased agency of young children to understand risk-taking behaviors, which in turn influence their decisions for or against taking risks (Cui and Xu 2007; Morrongiello et al. 2010, 2016). Identifying what may contribute to young children's risk-taking behaviors can help prevent their physical injuries (Lasenby-Lessard et al. 2013).

The current study focuses on two related but distinct aspects of children's understandings of risks: their evaluation of risk-taking and their general safety knowledge. Evaluation is based on children's perceptions as presented in the Health Belief Model (Janz and Becker 1984): the perception of injury vulnerability (e.g., children perceive themselves as vulnerable and likely to get hurt in a given situation) and the perception of potential 
severity (e.g., children perceive that they may get hurt badly if they fall). The Health Belief Model is commonly used to explain and predict health-related behaviors. It postulates that there is a clear connection between people's evaluation of the risk and severity of their own behaviors on the one hand, and their decision for or against certain behaviors on the other (Janz and Becker 1984). This understanding also applies to risk-taking behaviors in childhood (Zhang et al. 2013). Safety knowledge (e.g., safety rules and emergency tips) plays a similar role in influencing children's decisions for or against taking risks (Morrongiello et al. 2010). Evidence shows that 4 year olds are capable of identifying and avoiding risky behaviors that can cause bodily injuries (Morrongiello et al. 2016).

Research on the application of the Health Beliefs Model to the issue of preschoolers' unintentional injury leads us to propose a tripartite relation between children's evaluation of risk-taking behaviors, their safety knowledge, and their risk-taking behaviors (see Fig. 1). For example, children's risk-taking behavior is negatively correlated with their evaluation of such behavior as risky, and with their safety knowledge (Boles et al. 2005; Morrongiello and Lasenby 2007; Zeedyk and Wallace 2003). At the same time, there is a significantly positive correlation between children' evaluation of risk and their safety knowledge (Morrongiello and Lasenby 2007). However, a search of primary databases in China and in the US (i.e., the China National Knowledge Infrastructure and PsycINFO) did not yield any studies testing this tripartite relation, or the effects of child and family characteristics on the tripartite relation, in a preschool sample.

Around the globe, nearly $50 \%$ of children have suffered an unintentional injury (United Nations Children's Fund [UNICEF] 2014). Research has shown that the peak of physical injury occurs in preschool because preschoolers are developing motor skills that can support their curiosity to explore the world (Jiang et al. 2010; Li et al. 2012; Sun et al. 2014; Xu 2005), but they are inadequately regulated by their cognition. To our knowledge, almost all studies of young children's risk-taking in relation to their understandings of risk were conducted outside China, and most of these studies focused on elementary school and middle school students. Only in recent years did researchers in China begin treating early childhood injury as a rising public health issue (Xu et al. 2014). These injuries may affect more than 90.26 million Chinese children under age 6 (United Nations Children's Fund (UNICEF) 2014). Falls, road traffic accidents, and burns were identified as the causes of the most common injuries in China (Safe Kids China 2007). It was estimated that in China $41.4 \%$ of children under 14 who were unintentionally injured

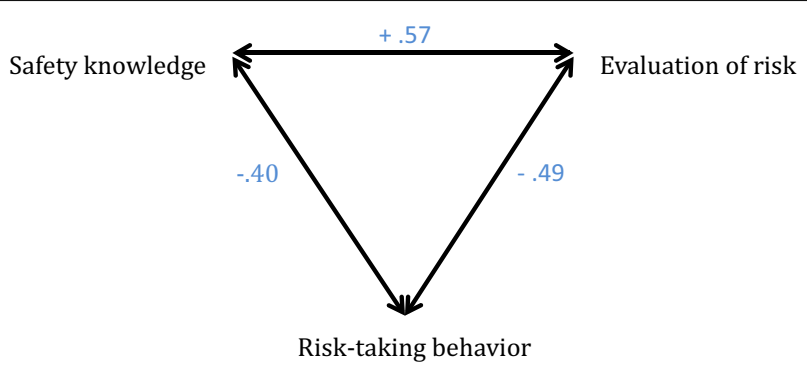

Fig. 1 Relations among the three components of the tripartite pattern 
were in the preschool age (Jiao et al. 2015). This rate of unintentional injuries in Chinese preschoolers is about 27\% higher than in the US and about 5\% lower than in India. More concerning is the rate of children's injury-caused deaths. Low- and middle-income countries such as China, Iran and Thailand have rates of injury-caused deaths that are on average 3.4 times higher than those in high-income countries such as the US, Australia, and the UK (WHO and UNICEF 2008).

Importantly, research focusing on either children's understandings of risk, or their risk-taking behaviors, has shown that child characteristics such as age, gender, number of siblings, and family characteristics such as caregivers' ethnicities, education, household income, location, and mobility, can exert great impact on children's safety behaviors (Cui and Xu 2007; Li 2009; Morrongiello and Lasenby 2007; Xu et al. 2014). It is conceivable that the impact of some of these characteristics (e.g., household income, location and mobility) is influenced by the rapid economic and societal development of today's China (United Nations Children's Fund [UNICEF] 2014). Thus, it is necessary to examine whether the proposed tripartite relation varies with respect to child, family, and residential characteristics, in order to inform early childhood educators and caregivers of possible ways to prevent unintentional injuries among preschoolers. The current study had two purposes. The first was to test if there was a tripartite relational pattern among Chinese preschoolers' evaluation of risk-taking behaviors, their safety knowledge, and their risk-taking behaviors. The second was to examine how the proposed tripartite relational pattern varied depending on diverse child, family and residential characteristics.

\section{Methods}

\section{Participants and procedures}

A total of 217 preschooler-caregiver dyads participated in this study. A caregiver in this study was the adult in the family who most often took care of the child; this could be a parent, a grandparent, a relative, or a nanny. We recruited caregivers from a municipality in northwestern China that had a population of approximately 400,000. Residents in the area included members of 37 ethnic minority groups, together constituting $25 \%$ of the local population. A similar proportion was made up of migrant workers. The municipality was in a plains region surrounded by an extensive rural area. A river meandered through its urban area. In this municipality, children attended preschools near their homes.

After receiving approval from the Institutional Review Board of the authors' institution and the permission of the local Bureau of Education, we selected at random four preschools (two rural and two urban) from a list of 22 local preschools provided by the Bureau. In the four preschools, we invited caregivers of children aged 3-5 to participate, without using any inclusion or exclusion criteria. Those who agreed to participate $(N=217)$ provided written consent. Children (girls $=102)$ whose caregivers signed the consent form met individually with two researchers in a preschool office for 10-15 min to complete the Child Questionnaire. One researcher asked the questions listed in the Child Questionnaire for each child to respond to, while the other recorded each response. The Child Questionnaire was used to measure preschoolers' evaluation of risky behavior, their safety knowledge, and their risk-taking behavior. Their caregivers completed a Parent Questionnaire that provided information about child, family, and 
residential demographic characteristics. All the participants spoke Putonghua, the common Chinese vernacular in China.

Table 1 lists descriptive information about demographic characteristics, including the child's age, gender, and only-child status; the parents' age, ethnicity, and caregiving role; and the family's socioeconomic status, residential area, and mobility. Note that the parents' ethnicity was classified as one of the two types: both parents were of the ethnic majority (Han) or one or both parents were ethnic minorities. The family socioeconomic status (SES) variable was created based on the parents' education and the family annual income in the unit of RMB (6.7 RMB $=\$ 1)$. There were four education-level scores: elementary school $=1$, middle and high schools $=2$; junior and 4 -year colleges $=3$, and

Table 1 Demographic characteristics $(N=217)$

\begin{tabular}{|c|c|c|c|}
\hline Type & Demographic variable & Value & Percentage (\%) \\
\hline \multirow[t]{7}{*}{ Child } & \multirow[t]{3}{*}{ Age by year } & 3 & 16.6 \\
\hline & & 4 & 46.1 \\
\hline & & 5 & 37.3 \\
\hline & \multirow[t]{2}{*}{ Gender } & Boy & 53.0 \\
\hline & & Girl & 47.0 \\
\hline & \multirow[t]{2}{*}{ Only-child status } & Yes & 72.4 \\
\hline & & No & 27.6 \\
\hline \multirow[t]{24}{*}{ Parents } & \multirow[t]{3}{*}{ Father's age } & $<30$ & 15.7 \\
\hline & & $30-35$ & 36.9 \\
\hline & & $>35$ & 47.5 \\
\hline & \multirow[t]{3}{*}{ Mother's age } & $<30$ & 28.1 \\
\hline & & $30-35$ & 44.7 \\
\hline & & $>35$ & 27.2 \\
\hline & \multirow[t]{2}{*}{ Father's ethnicity } & Majority (i.e., Han) & 89.4 \\
\hline & & Minority (e.g., Uigur, Kazak, Mongol) & 10.6 \\
\hline & \multirow[t]{2}{*}{ Mother's ethnicity } & Majority (i.e., Han) & 89.7 \\
\hline & & Minority (e.g., Uigur, Kazak, Mongol) & 10.3 \\
\hline & \multirow[t]{2}{*}{ Main caregiver(s) } & Both parents & 70.5 \\
\hline & & $\begin{array}{l}\text { Other than both parents (e.g., single } \\
\text { parent, grandparents, nurse) }\end{array}$ & 29.5 \\
\hline & \multirow[t]{4}{*}{ Father's education } & Primary school & 9.3 \\
\hline & & Middle or high school & 60.9 \\
\hline & & College & 27.0 \\
\hline & & Graduate school & 2.8 \\
\hline & \multirow[t]{4}{*}{ Mother's education } & Primary school & 12.1 \\
\hline & & Middle or high school & 52.3 \\
\hline & & College & 33.6 \\
\hline & & Graduate school & 1.9 \\
\hline & \multirow[t]{4}{*}{ Annual household income (RMB) } & $<30,000$ & 22.6 \\
\hline & & $30,000-60,000$ & 35.0 \\
\hline & & $60,000-90,000$ & 20.7 \\
\hline & & $>90,000$ & 21.7 \\
\hline \multirow[t]{4}{*}{ Residence } & \multirow[t]{2}{*}{ Mobility (years at current residence) } & $<10$ years & 34.7 \\
\hline & & $>10$ years & 65.3 \\
\hline & \multirow[t]{2}{*}{ Residential area } & Urban & 49.3 \\
\hline & & Rural & 50.7 \\
\hline
\end{tabular}


graduate school $=4$. There were five family income scores: less than $30,000 \mathrm{RMB}=1$; $30,000-60,000 \mathrm{RMB}=2 ; 60,000-90,000 \mathrm{RMB}=3 ; 90,000-120,000 \mathrm{RMB}=4$; and more than $120,000 \mathrm{RMB}=5$. These two categorical variables were converted into standardized $z$ scores, which then were summed to create a continuous family SES variable that was normally distributed, Skewness $=.11$, Kurtosis $=-.36$.

\section{Measures}

The Child Questionnaire and the Parent Questionnaire were developed in Chinese for the purposes of the current study. The Child Questionnaire was adopted from published instruments used by Chinese and international researchers (Hyder et al. 2009; Li 2009; Morrongiello et al. 2010; Shen 2009). It consisted of three parts: (1) nine open-ended questions about children's evaluation of risk-taking behaviors, including self-vulnerability and potential severity of risk-taking behaviors (e.g., "Tell me what would happen if you walk across the road alone?"); (2) twelve questions about the child's safety knowledge (e.g., "What is the place to cross the road?"; and (3) six yes-or-no items on prior risk-taking behaviors (e.g., "Have you ever climbed onto the windowsill?"). Following earlier studies in China (Li 2009; Safe Kids China 2007), we asked the child to recall three types of injury: fall, road traffic, and burn/fire, all of which were identified as the most common injuries among Chinese children. Limiting the focus to these three topics also kept the interview brief enough to be age-appropriate. The Parent Questionnaire was developed to collect child, family, and residential demographic information as shown in Table 1.

\section{Coding}

\section{Children's evaluation of risk-taking behaviors}

Each of the nine Child Questionnaire items used to assess children's evaluation of risktaking was scored 2 when children viewed the risk-taking behavior as a potential danger that could cause injury or lead to a severe consequence (e.g., the children stated that they could fall and get hurt if they jumped on the sofa); scored 1 when children focused on a possible action or a nonsevere consequence (e.g., the children stated that their mother was likely to pick them up if they jumped on the sofa); and scored 0 when children focused on the risk-taking behavior but showed no understanding of it (e.g., the children stated that it felt good to jump on the sofa). If the children gave two or more responses to a question, each response was scored and then a decision was made about the final score for the question. For example, if the children gave one response that was scored 1, and another response that was scored 2, the final score was the higher of the two values. The sum of all the scores from the nine items was used to represent the children's evaluation of risk-taking behaviors.

\section{Children's safety knowledge}

Each of the 12 safety knowledge items on the Child Questionnaire was given a score of 1 if the child answered the question correctly (e.g., the children knew they should apply cool water immediately after they were scalded); otherwise, a 0 (e.g., the children 
thought they should eat some candy after they were scalded). The sum of the scores represented children's level of safety knowledge.

\section{Children's risk-taking behaviors}

The six yes-or-no items in the Child Questionnaire were used to investigate whether the children engaged in the risk-taking behavior measured by each item (e.g., playing with fire, running across the road, and climbing on the windowsill). A score of 1 was given if the children had ever engaged in the behavior specified, regardless of the number of occurrences. The sum of the scores from all six items was the children's risk-taking experience score.

\section{Interrater reliability}

Two trained graduate students coded the data independently. An interrater reliability analysis of randomly selected items (30\%) showed consistency between raters: $\kappa=.89$ $(p<.001)$, 95\% CI (.790, .990).

\section{Data analysis}

Because the first purpose of this study was to test if there was a tripartite relational pattern, we used correlations to test the associations among evaluation of risk-taking behaviors, safety knowledge, and risk-taking behaviors. Then, for exploratory purposes, three multiple regressions were conducted to further examine these correlations. In each regression, two variables from the conceptual model, and the interaction of these variables, were tested as predictors of the third variable in the conceptual model. The second purpose of the study was to examine how the three components of the tripartite relational pattern varied by child, family and residential demographic characteristics. We used a series of multivariate analyses of variance (MANOVAs) to test the effects of various demographic characteristics on the set of three variables in the tripartite model.

\section{Results}

\section{Tripartite relational pattern}

The results of correlation analyses showed that Chinese preschoolers' risk-taking behavior was negatively correlated with both their evaluation of risk, $r(217)=-.49$, $p<.001$, and their safety knowledge, $r(217)=-.40, p<.001$ (see Table 2). As expected, there was a positive correlation between the preschoolers' evaluation of risk and their safety knowledge, $r(217)=.57, p<.001$. The three correlations constituted the proposed triangular relational pattern (see Fig. 1). The results of three multiple regressions also provided strong support for the tripartite model. That is, the correlation between any two variables remained significant even after taking into account the influence of the third variable. One regression model showed an interaction between children's safety knowledge and risk-taking behavior as a predictor of their evaluation of risky behaviors (see Table 3). Follow-up analysis suggested that the correlation between evaluation of risk and safety knowledge was stronger for children who took fewer risks.

The tripartite pattern was found in each of the three types of risk-taking (i.e. fall-, burn-, and traffic-related) as reported by children (see Table 2). For example, preschoolers' evaluation of fall-related behaviors as being dangerous, and their safety knowledge 


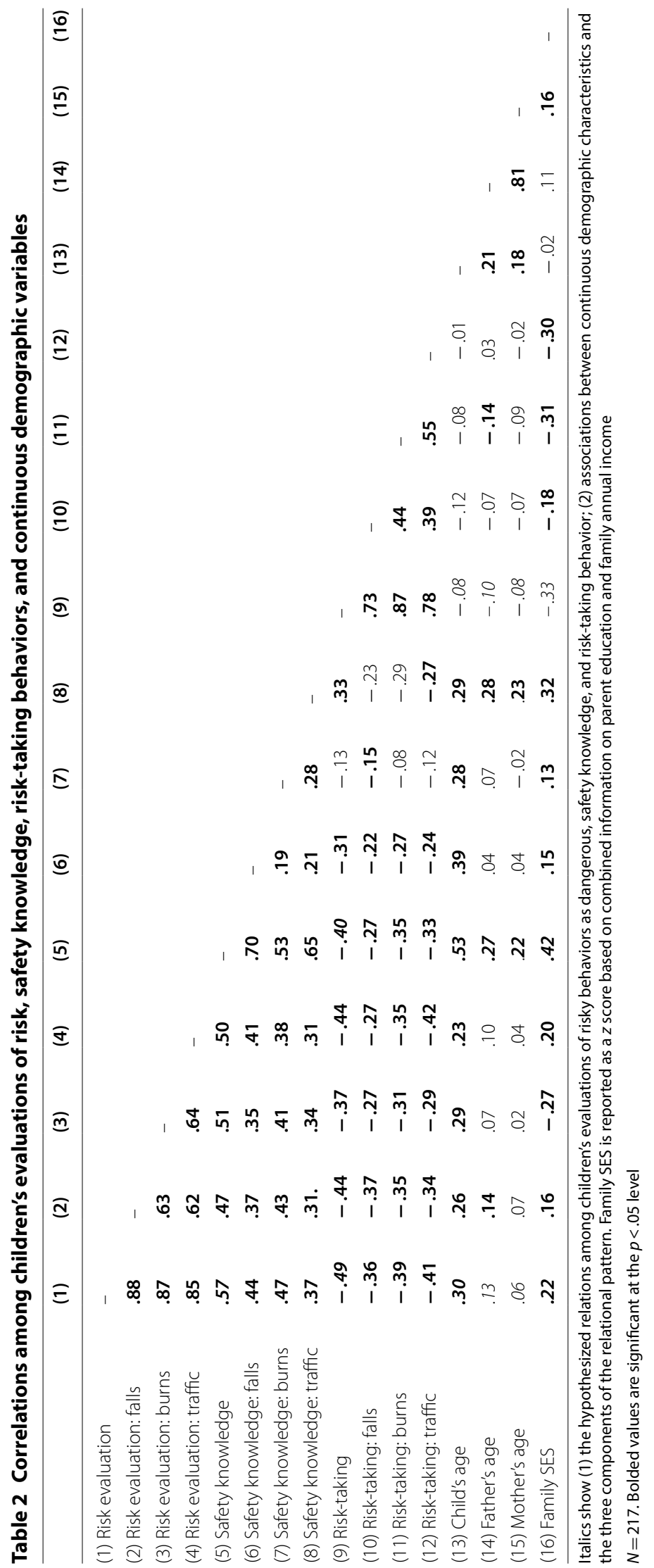


Table 3 Tests of the tripartite model: three multiple regression models

\begin{tabular}{|c|c|c|c|c|c|c|}
\hline Dependent variable & Independent variables & $\beta$ & $S E$ & $p$ & $R^{2}$ & Model Sig. \\
\hline \multirow[t]{4}{*}{ Risk evaluation } & Intercept & .07 & .06 & .197 & .43 & .000 \\
\hline & Safety knowledge & .42 & .06 & .000 & & \\
\hline & Risk-taking behavior & -.29 & .06 & .000 & & \\
\hline & Safety knowledge * risk-taking behavior & .18 & .05 & .001 & & \\
\hline \multirow[t]{4}{*}{ Safety knowledge } & Intercept & -.34 & .06 & .582 & .34 & .000 \\
\hline & Risk evaluation & .54 & .08 & .000 & & \\
\hline & Risk-taking behavior & -.16 & .06 & .017 & & \\
\hline & Risk evaluation * risk-taking behavior & -.07 & .06 & .262 & & \\
\hline \multirow[t]{4}{*}{ Risk-taking behavior } & Intercept & .06 & .07 & .360 & .26 & .000 \\
\hline & Risk evaluation & -.99 & .18 & .000 & & \\
\hline & Safety knowledge & -.39 & .15 & .009 & & \\
\hline & Risk evaluation * safety knowledge & -.23 & .12 & .061 & & \\
\hline
\end{tabular}

Bold italic values are significant at the $p<.001$ level

about falls, were negatively correlated with their reported fall-related risky behaviors, $r(217)=-.37, p<.001$ and $r(217)=-.22, p=.001$, respectively. Consistent with these findings, their safety knowledge about falls was positively correlated with their evaluation of fall-related risk behaviors as being dangerous, $r(217)=.37, p<.001$. The same tripartite relation also existed in the cases of burn-related and traffic-related risk-taking behaviors (see Table 2).

\section{The effects of demographic characteristics on components of the tripartite pattern}

Results of correlational analyses (see Table 2 ) showed that child age was positively correlated with evaluation of risky behaviors $(p<.001)$ and safety knowledge $(p<.001)$. However, children's self-reported risk behaviors were not associated with their age $(p=.272)$. Both father's age and mother's age were positively correlated with their child's safety knowledge $(p<.001, p=.001$, respectively). High family SES was associated with higher evaluation of risk-taking behaviors $(p=.001)$, higher safety knowledge $(p<.001)$, and less risk-taking behavior in preschoolers $(p<.001)$.

Table 4 shows the means and standard deviations of the three dependent measures (risk evaluation, safety knowledge, and risk-taking) for each level of the categorical demographic variables. Table 5 shows the results of a series of three MANOVAs. Each MANOVA included two categorical demographic variables, and their interaction, as independent variables; children's risk evaluation, safety knowledge, and risk-taking made up the set of dependent variables. If the multivariate $F$ value for an independent variable was significant, we then examined the univariate $F$ values for the three dependent variables to determine which dependent variable(s) contributed significantly to the multivariate effect (see Table 5).

The first MANOVA tested the child's gender and only child status, and the interaction of these variables, as predictors of the set of three dependent variables. The results showed that being an only child was a significant predictor $(p=.004)$. Univariate tests indicated that compared to children with siblings, only children had higher evaluation of risk $(p=.007)$, higher safety knowledge $(p=.001)$, and fewer risk-taking behaviors $(p=.010)$. The second MANOVA tested parents' ethnicity and main caregiver status as 
Table 4 Evaluations of risk, safety knowledge, and risk-taking behaviors by demographic characteristics

\begin{tabular}{|c|c|c|c|}
\hline & $\begin{array}{l}\text { Risk evaluation } \\
M(S D)\end{array}$ & $\begin{array}{l}\text { Safety knowledge } \\
M(S D)\end{array}$ & $\begin{array}{l}\text { Risk-taking } \\
M(S D)\end{array}$ \\
\hline \multicolumn{4}{|l|}{ Child's gender } \\
\hline Girls & $12.51(3.99)$ & $8.78(3.35)$ & $2.94(2.07)$ \\
\hline Boys & $12.65(4.60)$ & $9.13(3.67)$ & $3.23(2.16)$ \\
\hline \multicolumn{4}{|l|}{ Only child status } \\
\hline Not only child & $11.29(5.16)$ & $7.64(3.28)$ & $3.69(2.21)$ \\
\hline Only child & $13.07(3.89)$ & $9.47(3.50)$ & $2.87(2.05)$ \\
\hline \multicolumn{4}{|l|}{ Parents' ethnicity } \\
\hline Minorities & $9.43(6.21)$ & $7.32(4.32)$ & $4.21(2.11)$ \\
\hline Majority (Han) & $13.05(3.77)$ & $9.21(3.33)$ & $2.93(2.07)$ \\
\hline \multicolumn{4}{|l|}{ Main caregiver } \\
\hline Other than both parents & $12.48(4.63)$ & $9.19(3.70)$ & $2.98(2.10)$ \\
\hline Both parents & $12.63(4.20)$ & $8.88(3.45)$ & $3.14(2.13)$ \\
\hline \multicolumn{4}{|l|}{ Residential area } \\
\hline Rural & $11.16(5.04)$ & 7.33 (3.19) & $3.96(2.00)$ \\
\hline Urban & $14.05(2.77)$ & $10.65(3.03)$ & $2.20(1.86)$ \\
\hline \multicolumn{4}{|l|}{ Residential mobility } \\
\hline Low mobility & $13.29(3.83)$ & $9.76(3.42)$ & $2.69(2.03)$ \\
\hline High mobility & $11.29(4.90)$ & $7.52(3.27)$ & $3.07(2.11)$ \\
\hline
\end{tabular}

Table 5 MANOVA results by categorical demographic characteristics

\begin{tabular}{|c|c|c|c|c|c|c|c|c|}
\hline \multirow[t]{2}{*}{$\begin{array}{l}\text { Demographic } \\
\text { characteristics }\end{array}$} & \multirow[t]{2}{*}{ Wilks' Lambda } & \multirow[t]{2}{*}{$\begin{array}{l}\text { Multivariate } \\
F(3,210)\end{array}$} & \multicolumn{2}{|c|}{ Risk evaluation } & \multicolumn{2}{|l|}{$\begin{array}{l}\text { Safety } \\
\text { knowledge }\end{array}$} & \multicolumn{2}{|l|}{$\begin{array}{l}\text { Risk-taking } \\
\text { behavior }\end{array}$} \\
\hline & & & $\begin{array}{l}\text { Univariate } \\
F(1,212)\end{array}$ & $\eta^{2}$ & $\begin{array}{l}\text { Univariate } \\
F(1,212)\end{array}$ & $\eta^{2}$ & $\begin{array}{l}\text { Univariate } \\
F(1,212)\end{array}$ & $\eta^{2}$ \\
\hline \multicolumn{9}{|l|}{ Child's } \\
\hline Gender & .99 & .46 & .00 & .000 & .18 & .001 & .72 & .003 \\
\hline Only child status & .94 & 4.59 & 7.31 & .033 & 11.67 & .052 & 6.75 & .031 \\
\hline $\begin{array}{l}\text { Gender*only child } \\
\text { status }\end{array}$ & 1.00 & .10 & .09 & .000 & .11 & .001 & .03 & .000 \\
\hline \multicolumn{9}{|l|}{ Parents' } \\
\hline Ethnicity & .92 & 5.87 & 14.73 & .065 & 7.42 & .034 & 10.64 & .048 \\
\hline Main caregiver & 1.00 & .23 & .32 & .001 & .04 & .000 & .09 & .000 \\
\hline $\begin{array}{l}\text { Ethnicity*main } \\
\text { caregiver }\end{array}$ & .98 & 1.27 & .62 & .003 & .20 & .001 & 1.12 & .005 \\
\hline \multicolumn{9}{|l|}{ Residential } \\
\hline Area & .79 & 19.19 & 17.58 & .077 & 40.71 & .161 & 30.78 & .127 \\
\hline Mobility & .96 & 2.71 & 2.98 & .014 & 6.42 & .029 & 3.55 & .016 \\
\hline Area*mobility & 1.00 & .23 & 2.58 & .001 & .33 & .002 & .50 & .002 \\
\hline
\end{tabular}

predictors of the set of three dependent variables. The results showed that parent ethnicity was a significant predictor $(p=.001)$. Univariate tests indicated that compared to children with Han parents, children with ethnic minority parents had lower evaluation 
of risk $(p=.001)$, lower safety knowledge $(p=.007)$, and more risk-taking behaviors $(p=.004)$. In the third MANOVA, residential area, mobility, and the interaction of these two variables, were tested as predictors of the set of three dependent variables. The results showed that both residential area and residential mobility were significant predictors $(p<.001, p=.046$, respectively). Univariate tests indicated that compared to rural children, urban children had higher evaluation of risk $(p<.001)$, higher safety knowledge $(p<.001)$, and fewer risk-taking behaviors $(p<.001)$. However, despite the significant multivariate $F$ for residential mobility, univariate tests indicated that no single dependent measure contributed significantly more than any other to the multivariate effect. There was a trend for children whose family had higher residential mobility to experience lower evaluation of risk $(p=.086)$, lower safety knowledge $(p=.012)$, and more risk-taking behaviors $(p=.061)$.

\section{Discussion}

In this study, we built on previous research to propose a tripartite association among factors that may underlie preschoolers' unintentional injury: evaluation of risk behaviors, safety knowledge, and risk-taking behavior. Our data showed evidence of this tripartite pattern in our sample of Chinese preschoolers. Children who evaluated risktaking behaviors as dangerous, and who had higher safety knowledge, were less likely than their peers to engage in risky behaviors. In line with the Health Belief Model (Janz and Becker 1984), the results demonstrate a clear association between preschoolers' understandings and behaviors, confirming the application of the model specifically in the field of research on preschoolers' unintentional injury.

Furthermore, as the first study in China to focus on preschoolers' cognitive understandings of risk and risk-taking behaviors, this study examined the tripartite pattern in the context of important demographic characteristics that may be related to unintentional injury. Our results showed that preschoolers with one of four demographic characteristics (i.e., rural residency, non-only-child status, low family SES, or high mobility) may be at higher risk for unintentional injury than their peers. Children in these groups reported more risky behaviors than other preschoolers, along with the groups with less of an understanding of the behaviors, are risky. These findings are consistent with those reported in the extant literature for older children (Fonseca et al. 2002; Li et al. 2012; Shen 2009; Xu et al. 2014).

In addition to the four demographic characteristics just listed, parental ethnicity appeared to have an effect on children's understandings and behaviors. Specifically, children with ethnic minority parents may be at higher risk for unintentional injury than other groups in the sample. However, this conclusion, although based on statistically significant results, should be interpreted with caution due to the imbalance in group sizes, with $75 \%$ of parents being of the Han majority and $25 \%$ being from ethnic minority groups. On the one hand, this sample has the advantage of being remarkably diverse; for example, in China as a whole, minorities make up only $8.41 \%$ of the population (National Bureau of Statistics of China 2011). On the other hand, even a very diverse sample can be insufficient for typical quantitative methods. This suggests a sampling challenge for future research: the distribution of ethnic minority families may call for incorporating purposeful sampling used in qualitative research (e.g., Cresswell and Plano Clark 2011; 
Patton 2002) rather than randomly selecting from all available preschools. It also suggests that as in the United States and elsewhere, different ethnic groups utilize childcare service significantly differently owing to their specific economic and cultural contexts (Child Trends Databank 2016; Liang et al. 2000; OECD 2016).

Interestingly, our results concerning gender were inconsistent with a widely documented pattern of boys being more prone to risky behaviors and injury because they are more likely than girls to take risks in daily activities, and because they receive less adult supervision than do girls (Reading et al. 2009; World Health Organization 2008). However, our finding is in company with a few other studies in China that did not find the expected associations between gender and risk behaviors, and between gender and understandings (Cui and Xu 2007; Fang 2014; Zhang and Zhu 2006). It is possible that boys and girls are vulnerable to different subtypes of risk-taking behaviors. One study examined risk-taking-related injuries in 488 children younger than seven and did not find an overall gender difference, but reported that boys were more likely to be bitten by animals, while girls had more traffic injuries (Fang 2014). This could be a focus of future research on gender differences in relation to the tripartite relation.

Another interesting result was that children who did and who did not have parents as the main caregivers did not differ in their evaluations of risk, safety knowledge, or risk-taking behaviors. These results suggest that nonparental caregivers may be just as effective as parents in preventing preschoolers' risk-taking behaviors. Other studies have shown that Chinese grandparents are more likely than parents to guard grandchildren against risks, lowering risk-taking behaviors of the young (Chen et al. 2014; Lei 2011). By contrast, the World Health Organization reported that parents surpassed grandparents in restraining young children from risky exploration and in giving them safety education (World Health Organization 2008). Curiously, although Chinese grandparents play a significant role in families' childcare (Chen et al. 2014), their role in promoting children's cognitive development (including evaluation of risk and safety knowledge) is little researched. The current study suggests that grandparent caregivers' role in shaping the tripartite pattern merits careful evaluation.

It is worth noting that multiple regression analyses showed a significant interaction between safety knowledge and risk-taking behavior in predicting risk evaluation among the preschoolers. Further analysis showed that the low risk-taking preschoolers' safety knowledge had correspondingly low evaluative ability. In other words, their safety knowledge and evaluative ability went hand in hand. However, for the high risk-taking preschoolers, safety knowledge and evaluative ability were less highly correlated. Their evaluative ability may grow at a somewhat faster pace as they gain safety knowledge side by side with the low risk-taking preschoolers. Because the regression analysis was exploratory in this study, this interaction effect suggests a need for future research to examine whether high risk-taking preschoolers can substantially benefit from safety knowledge more than low risk-taking preschoolers. This issue may have some import for prevention education.

Our findings have valuable implications for improving preschoolers' early evaluations of risk and safety knowledge, and for reducing risk-taking behaviors. For one thing, the tripartite pattern can draw practitioners' attention to the interaction between preschoolers' risk-taking behaviors and their understandings of such behaviors. For another, this 
study reveals the safety needs of specific groups of Chinese preschoolers who appear to be at higher risk than their peers, namely rural children, non-only children, children from low SES families, and high mobility families. These caregivers may be less educated and less involved in guiding, supervising, and educating their children than other parents (Lahaie et al. 2009; Wang and Mesman 2015; Zhao and 2014). As a result, their children may engage in risky behaviors and suffer negative consequences that affect their physical and psychological wellbeing (Li et al. 2012).

A prevention program should inform and help caregivers, teachers, and other helping professionals to focus more on these vulnerable children in China and allocate more resources to improve preschoolers' safety knowledge and understandings at appropriate age levels. This type of prevention program could improve young children's understandings of risks and their evaluative skills by discussing with them possible scenarios they might encounter daily at home, in preschool, on the playground, on the street, and in commercial settings. The scenarios could allow discussion of other topics as well, such as the difference between small risks (e.g., during play) and large risks of the kind that result in injury. Once a pedagogical approach is effectively worked out, the prevention program should bring parents and grandparents into co-learning of safety knowledge and evaluative skills with children, to support children's growth and development in all settings. Particularly in China where the centralized governing system is prevalent, if a prevention program proves effective at the local level, a top-down approach can be mobilized for dissemination across the municipality and beyond.

As a side note, although we limited the injury types to the most common ones in part to facilitate children's recall, some preschoolers might nevertheless have failed to remember their past risk-taking behaviors (Krosnick and Presser 2010). In addition, sometimes preschoolers can be unwilling to report their own risk-taking behaviors if they perceive that such behaviors are undesirable to adults (Arseneault et al. 2005). To overcome these two difficulties, in future research, we will solicit preschoolers' free recall on the one hand, and ask parents to report their children's past risk-taking behaviors on the other, to gauge the accuracy of children's self-reports. Having multiple reporters will also help address a limitation of the current study, namely that all data were collected through child report, creating shared method variance that might help inflate correlation values.

\section{Conclusion}

In keeping with the Health Belief Model (Janz and Becker 1984) and previous studies, the current study was the first in China to test the proposed tripartite relational pattern in preschoolers' evaluation of risk, safety knowledge, and risk-taking behaviors. This study was also the first to examine variations in the components of the tripartite pattern in the context of important demographic characteristics that might affect these associations. This study is one of the few that have applied the Health Belief Model to early childhood populations (e.g., Morrongiello et al. 2016 on 6 year olds), and is the first to extend this line of research to preschoolers of ages 3-5. The findings in China's changing society suggest that preschool injury prevention programs could take into account child, family, and residential characteristics to contextualize children's risk-taking and their incurring unintentional injury, and at the same time develop both preschoolers' and caregivers' safety knowledge and evaluative skills. 


\section{Authors' contributions}

This article was written by $\mathrm{JH}$ and supervised by $\mathrm{YH}$. All authors worked equally on the first and final drafts of this manuscript. Both authors read and approved the final manuscript.

\section{Acknowledgements}

Not applicable.

\section{Competing interests}

The authors declare that they have no competing interests.

\section{Availability of data and materials}

Information of data and materials is given in main text of the article. Demographic details of participants are shown in Table 1. Materials (i.e., the Child Questionnaire) are available if required. As IRB (Institutional Review Board) requires maintaining data confidentiality, raw data are stored at the University of Memphis.

\section{Ethics approval and consent to participate}

This study has been approved by the Institutional Review Board at the University of Memphis.

\section{Funding}

Not applicable

\section{Publisher's Note}

Springer Nature remains neutral with regard to jurisdictional claims in published maps and institutional affiliations.

Received: 6 January 2018 Accepted: 21 August 2018

Published online: 27 August 2018

\section{References}

Arseneault, L., Kim-Cohen, J., Taylor, A., \& Moffitt, T. E. (2005). Psychometric evaluation of 5- and 7-year-old children's selfreports of conduct problems. Journal of Abnormal Child Psychology, 33(5), 537-550.

Boles, R. E., Roberts, M. C., Brown, K. J., \& Mayes, S. (2005). Children's risk taking behaviors: The role of child-based perceptions of vulnerability and temperament. Journal of Pediatric Psychology, 30, 562-570.

Chen, L., Zhang, Y., \& Chen, C. (2014). The advantages and disadvantages of grandparents' upbringing: Its influence on grandparents, parents, and grandchildren. Chinese Journal of Early Childhood Education (Educational Sciences), 616, 52-56.

Child Trends Databank (2016). Child care: Indicators on children and youth. http://www.childtrends.org/wp-content/ uploads/2016/05/21_Child_Care.pdf.

Cresswell, J. W., \& Plano Clark, V. L. (2011). Designing and conducting mixed methods research (2nd ed.). Thousand Oaks: Sage.

Cui, W., \& Xu, Y. (2007). The relationship between preschoolers' understanding of unintentional injury and risk taking behaviors. Chinese Journal of Maternal and Child Health Care, 22, 3094-3096.

Fang, L. (2014). Related factor analysis of 488 cases of unintentional injury of children under 7 years old. Chinese Journal of Child Health Care, 22(1), 98-100.

Fonseca, S. S., Victora, C. G., Halpern, R., Barros, A. J., Lima, R. C., Monteiro, L. A., et al. (2002). Risk factors for accidental injuries in preschool children. Journal of Pediatrics, 78(2), 97-104.

Hyder, A. A., Sugerman, D. E., Puvanachadra, P., Razzak, J., El-Sayed, H., Isaza, A., et al. (2009). Global childhood unintentional injury surveillance in four cities in developing countries: A pilot study. Bulletin of the World Health Organization, $87,345-352$.

Janz, N. K., \& Becker, M. H. (1984). The Health Belief Model: A decade later. Health Education Quarterly, 11, 1-47.

Jiang, X., Zhang, Y., Wang, Y., Wang, B., Xu, Y., \& Shang, L. (2010). An analysis of 6215 hospitalized unintentional injuries among children aged 0-14 in northwest China. Accident Analysis and Prevention, 42(1), 320-326.

Jiao, F., Zhang, Y., \& Wang, L. (2015). Analysis of 537 cases of children's unintentional injury. Chinese Henan Journal of Preventive Medicine, 5, 408-410.

Krosnick, J. A., \& Presser, S. (2010). Question and questionnaire design. In P. H. Rossi, J. D. Wright, \& A. B. Anderson (Eds.), Handbook of survey research (pp. 263-313). New York: Academic Press.

Lahaie, C., Hayes, J. A., Piper, T. M., \& Heymann, J. (2009). Work and family divided across borders: The impact of parental migration on Mexican children in transnational families. Community, Work and Family, 12(3), 299-312.

Lasenby-Lessard, J., Morrongiello, B. A., \& Barrie, D. (2013). The impact of accumulated experience on children's appraisals of risk and risk-taking decisions: Implications for youth injury prevention. Health Psychology, 32(4), 370-378.

Lei, N. (2011). Interventions with parents and grandparents for 2-4 year old children's play activity (Master thesis). Available from Chinese National Knowledge Infrastructure (CNKI) database.

Li, S. (2009). Study on epidemiological characteristics and influencing factors of unintentional injuries among children in PuCheng County (Master's thesis). Available from Chinese National Knowledge Infrastructure (CNKI) database.

Li, X., Wang, L., Liu, X., Xia, J., Qiu, M., Tian, H., et al. (2012). Intervention for pre-school children's family unintentional injury. Chinese Journal of Preventive Medicine Information, 28, 411-413.

Liang, X., Fuller, B., \& Singer, J. (2000). Ethnic differences in child care selection: The influence of family structure, parental practices, and home language. Early Childhood Research Quarterly, 15(3), 357-384. 
Morrongiello, B. A., Bell, M., Park, K., \& Pogrebtsova, K. (2016). Evaluation of the Safety Detective Program: A classroombased intervention to increase kindergarten children's understanding of home safety hazards and injury-risk behaviors to avoid. Prevention Science, 17(1), 102-111.

Morrongiello, B. A., Cusimano, M., Barton, B. K., Orr, E., Chipman, M., Tyberg, J., et al. (2010). Development of the BACKIE questionnaire: A measure of children's behaviors, attitudes, cognitions, knowledge, and injury experiences. Accident Analysis and Prevention, 42, 75-83.

Morrongiello, B. A., \& Lasenby, J. (2007). The psychology of risk-taking by children: An integrative model and implications for interventions. Injury Prevention, 13, $20-25$.

National Bureau of Statistics of China (2011). Press release on major figures of the sixth China census. http://www.stats .gov.cn/tjjs/zxfb/201104/t20110428_12707.html.

OECD. (2016). Who uses childcare? Background brief on inequalities in the use of formal early childhood education and care (ECEC) among very young children. Paris: Organization for Economic and Cooperation Development.

Patton, M. Q. (2002). Qualitative research and evaluation methods (3rd ed.). Thousand Oaks: Sage Publications.

Reading, R., Jones, A., Haynes, R., Daras, K., \& Emond, A. (2009). Individual factors explain neighborhood variations in accidents to children under 5 years of age. Social Science and Medicine, 67, 915-927.

Safe Kids China. (2007). Analysis report on unintentional injury in Chinese children. http://www.safekidschina.org/index .php?classid $=4452 \&$ newsid $=6367 \& \mathrm{t}=$ show.

Shen, M. (2009). Epidemiological characteristics of unintentional injuries and evaluation of the intervention model for children in rural China (Doctoral dissertation). Available from Chinese National Knowledge Infrastructure (CNKI) database.

Sun, Y., Lv, C., Wang, W., Zhang, C., Bai, Y., Wu, D., et al. (2014). Analysis of research status of childhood unintentional injury. Chinese Journal of Rehabilitation Theory and Practice, 20, 176-179.

United Nations Children's Fund (UNICEF). 2014. Census data about children in China. http://www.unicef.cn/en/publicatio ns/comprehensive/2040.html.

Wang, L., \& Mesman, J. (2015). Child development in the face of rural-to-urban migration in China: A meta-analytic review. Psychological Science, 10, 813-831.

World Health Organization (WHO) and United Nations Children's Fund (UNICEF). (2008). World report on child injury prevention. Geneva: WHO Press.

Xu, S. (2005). Relationships between behavioral health status and epidemiologic characteristics of unintentional injuries off children at 3-7 (Master thesis). Available from Chinese National Knowledge Infrastructure (CNKI) database.

Xu, T., Gong, L., Wang, H., Zhang, R., Wang, X., \& Kaime-Atterhog, W. (2014). Epidemiology of unintentional injuries among children under six years old in floating and residential population in four communities in Beijing: a comparative study. Maternal Child Health Journal, 18(4), 911-919.

Zeedyk, M. S., \& Wallace, L. (2003). Tackling children's road safety through edutainment: An evaluation of effectiveness. Health Education Research, 18, 493-505.

Zhang, L. L., Dalal, K., \& Wang, S. M. (2013). Injury related risk behavior: A Health Belief Model-based study of primary school students in a safe community in Shanghai. PLOS ONE, 8(8), e70563.

Zhang, P., \& Zhu, Y. (2006). Preschoolers' understandings of unintentional injury. Chinese Journal of Child Health Care, 14(5), 511-513.

Zhao, Q., Yu, X., Wang, X., \& Glauben, T. (2014). The impact of parental migration on children's school performance in rural China. China Economic Review, 31, 43-54.

\section{Submit your manuscript to a SpringerOpen ${ }^{\circ}$ journal and benefit from:}

- Convenient online submission

- Rigorous peer review

- Open access: articles freely available online

High visibility within the field

Retaining the copyright to your article

Submit your next manuscript at $\mathbf{s p r i n g e r o p e n . c o m ~}$ 